\title{
PENGARUH FILM GURU BANGSA: TJOKROAMINOTO TERHADAP RASA NASIONALISME REMAJA SISWA-SISWI SMU NEGERI 4 DEPOK
}

\author{
THE INFLUENCE OF FILM GURU BANGSA: TJOKROAMINOTO TO THE \\ NATIONALISM TENAGEERS OF STUDENTS SMU NEGERI 4 DEPOK
}

\author{
Damayanti ${ }^{1}$, Azwar ${ }^{2}$
}

\begin{abstract}
ABSTRAK
Hasil penelitian secara deskriptif menunjukkan bahwa pengaruh tayangan film Guru Bangsa: Tjokroamnoto Pengaruh film Guru Bangsa: Tjokroaminoto terhadap rasa nasionalisme remaja siswa-siswi SMUN 4 Depok, secara keseluruhan tinggi baik dari segi Nasionalisme Kemandirian Bangsa, Nasionalisme Agama, dan Nasionalisme Sekuler. Sementara penayangan film Guru Bangsa: Tjokroaminto terhadap rasa Nasionalisme Anti Agama (Komunis) rendah atuau tidak terdapat pengaruh. Terdapat perbedaan nyata pada rasa Nasionlaisme Kemandirian Bangs, Nasionalisme Agama dan Nasionalisme Sekuler, serta tidak ada perbedaan untuk aspek Nasionalisme Anti Agama (Komunis) antara siswa-siswi dalam kelompok eksperimen yang mendapat tayangan film Guru Bangsa: Tjokroaminoto dengan kelompok kontrol yang tidak mendapat tayangan film Guru Bangss: Tjokroaminoto. Secara umum faktor-faktor dalam film Guru Bangsa: Tjokroaminoto yang berpengaruh tinggi terhadap rasa nasionalisme remaja siswa-siswi SMU N 4 Depok adalah faktor Media dan aspek komunikan, sedangkan faktor karakteristik komunikator dan Isi Pesan dalam film Guru Bangsa: Tjokroaminoto berpengaruh rendah terhadap rasa nasionalsme remaja siswa-siswi SMUN 4 Depok.
\end{abstract}

Kata Kunci - Tayangan film, Rasa nasionalisme, Remaja

\section{ABSTRACT}

The result of research shows that the influence of film overall high, both in terms of Nationalism Independence of Nations, Religious Nationalism, and Secular Nationalism. While the screening of Teachers of the Nation: Tjokroaminto to the sense of Nationalism Anti-Religion (Communist) is low.Here is a significant difference in the sense of Nasionlaism Independence of Nations, Nationalism of Religion and Secular Nationalism, and there is no difference to the aspect of Anti-Religious Nationalism (Communism) between students in the experimental group that received the movie of Guru Bangsa: Tjokroaminoto with control group that was not getting impressions movie Guru Bangsa: Tjokroaminoto. In general, the factors in the film Guru Bangsa: Tjokroaminoto which has a high influence on the nationalism of teenagers of SMU N 4 Depok, is the factor of Media and communicant aspects, while the communicator characteristic factor and Message content in Guru Bangsa: Tjokroaminoto have low effect on nationalism teenage students of SMUN 4 Depok.

Keywords - Movie Impressions, Sense of nationalism, Youth

\footnotetext{
${ }^{1}$ Fakultas Ilmu Sosial dan Ilmu Politik UPN “Veteran” Jakarta. damay.masduki@gmail.com

${ }^{2}$ Fakultas Ilmu Sosial dan Ilmu Politik UPN “Veteran” Jakarta. azwarsutanmalaka@gmail.com
} 


\section{PENDAHULUAN}

Perkembangan ilmu pengetahuan dan teknologi telah berdampak pada percepatan informasi dan akses informasi, sehingga semua orang bisa dengan cepat dan mudah memperoleh informasi. keadaan seperti ini lambat laun akan semakin membuat orang semakin susah bersosialisasi, karena mereka lebih senang menghabiskan waktu dengan smartphone atau gadget. Mengakibatkan adanya kesenjangan sosial yang tajam antara yang kaya dan miskin, karena adanya persaingan bebas dalam globalisasi ekonomi. Hal tersebut dapat menimbulkan pertentangan antara yang kaya dan miskin yang dapat mengganggu kehidupan nasional bangsa. Munculnya sikap individualisme yang menimbulkan ketidak pedulian antarperilaku sesama warga. Dengan sikap indivudual maka masyarakat kurang peduli dengan kehidupan bangsa.

“... nasionalisme mencakup banyak aspek yang apabila diteliti cukup kompleks. Pertama, nasionalisme mereflesikan sejarah masa lalu, khususnya mencakup kisah perjalanan hidup atau proses terbentuknya suatu bangsa yang disebut nasion. Aspek historis yang dikandungnya menyebabkan nasionalisme setiap bangsa tidak sama. Tidak saja bagi orang-orang disatu generasi yang berada di negara-negara berbeda di satu negara yang sama. Dimensi tempat dan waktu merupakan aspek penting untuk memahami nasionalisme suatu bangsa, namun kedua dimensi ini pula sering dilupakan, terutama dimensi kedua, yaitu waktu, (Sudarsono, 2011, hlm.7-8).

Menurut Budiono (2007) Rendahnya semangat nasionalisme masyarakat Indonesia sangatlah memprihatinkan. Masyarakat yang seharusnya lebih mencintai dan menghargai budaya bangsa sendiri ternyata lebih menganut dan mengagumi budaya bangsa lain. Menurunnya semangat nasonalisme tersebut mungkin disebabkan karena kurangnya pemahaman mayarakat akan arti penting rasa nasionalisme. Rasa nasionalisme terhadap tanah air tidak hanya di tunjukkan dengan adanya upacara bendera pada saat hari kemerdekaan saja, tetapi juga bisa dapat dikembangkan dalam hal lain. Mengembangkan potensi diri dengan keseniaan daerah, mengikuti perlombaan dalam bidang pelajaran tertentu atau olah raga yang dapat mengharumkan nama Indonesia di mata dunia. Tidak malah membanggakan bangsa lain dengan cara meniru gaya hidup bangsa lain.

Salah satu film yang berlatar perjuangan nasional adalah film Guru Bangsa: Tjokroaminoto. Film yang disutradarai Garin Nugroho ini bercerita tentang hidup-juang salah satu tokoh pioneer pergerakan modern Indonesia, Haji Oemar Said Tjokroaminoto (diperankan Reza Rahardian). Kisah dimulai dengan Tjokro kecil yang melihat 66 | Pengaruh Film Guru Bangsa: Tjokroaminoto Terhadap... 
penderitaan pekerja-pekerja perkebunan kapas yang dianiaya oleh mandor-mandor Belanda. Kegelisahan Tjokro terhadap keadaan juga diperlihatkannya di sekolah, dimana dia berani berdebat dengan guru Belanda totok. Sementara itu narasi-narasi agama Islam yang kuat tentang "hijrah" pada akhirnya berperan membentuk karakter dan kesadaran Tjokro terhadap posisi pribumi terhadap kolonial. Dan ketika beranjak dewasa, Tjokro pun mulai bertindak.

Karena berawal dari penghormatan, film Guru Bangsa:Tjokroaminoto bisa menjadi contoh bagi penonton terutama kalangan remaja untuk belajar sejarah dan menghormati pahlawan yang telah memberikan rasa nasionalisme mereka terhadap bangasa Indonesia.

Berdasarkan latar belakang yang telah diuraikan oleh penulis diatas, maka dapat dirumuskan permasalahan dalam penelitian yaitu:

1. Apakah terdapat pengaruh film Guru Bangsa: Tjokroaminoto terhadap Rasa Nasionalisme pada siswa siswi SMU Negeri 4 Depok?

2. Seberapa besar pengaruh film Guru Bangsa: Tjokroaminoto terhadap Rasa Nasionalisme pada siswa siswi SMU Negeri 4 Depok?

Secara umum penelitian ini bertujuan untuk mengetahui pengaruh film, secara sfesifik bertujuan:

1. Untuk mengetahui adanya pengaruh film Guru Bangsa: Tjokroaminoto terhadap sikap nasionalisme pada siswa-siswi SMU Negeri 4 Depok.

2. Untuk mengetahui besarnya pengaruh Film Guru Bangsa: Tjokroaminoto terhadap Rasa Nasionalisme pada siswa siswi SMU Negeri 4 Depok.

\section{A. Komunikasi Massa}

Komunikasi massa dapat didefinisikan sebagai proses komunikasi yang berlangsung di mana pesannya dikirim dari sumber yang melembaga kepada khalayak yang sifatnya massal melalui alat-alat yang bersifat mekanis seperti radio, televisi, surat kabar, dan film. (Cangara, 2009, hlm 126)

Schramm (Ardianto, Elvinaro \& Erdinaya., 2004) mengatakan, untuk berlangsungnya suatu kegiatan komunikasi minimal diperlukan tiga komponen yaitu: source, message dan destination, atau komunikator, pesan, dan tujuan berkomunikasi. 
Lasswell (Ardianto, Elvinaro \& Erdinaya, 2004) seorang ahli politik di Amerika Serikat mengemukakan formula yang dapat dilihat pada Gambar 1 berikut ini:

\begin{tabular}{|c|c|c|c|c|}
\hline WHO & SAYS WHAT & $\begin{array}{c}\text { IN WHICH } \\
\text { CHANNEL }\end{array}$ & TO WHOM & $\begin{array}{c}\text { WITH WHAT } \\
\text { EFFECT }\end{array}$ \\
\hline Siapa & Berkata apa & $\begin{array}{c}\text { Melalui saluran } \\
\text { apa }\end{array}$ & Kepada siapa & $\begin{array}{c}\text { Dengan Efek } \\
\text { Apa }\end{array}$ \\
\hline Komunnikator & Pesan & Media & Penerima & Efek \\
\hline Control Studies & Analisis Pesan & Analisis Media & Analisis & Analisis Efek \\
& & & Khalayak & \\
\hline
\end{tabular}

Gambar 1. Formula Lasswell (Ardianto, Elvinaro \& Erdinaya, 2004)

\section{B. Teori Stimulus Respons (S-R)}

Dalam buku Manajemen Media Penyiaran oleh Morissan (2008) Teori S-R ini biasa disebut juga teori jarum hipodermik atau teori peluru. Disebut demikian, karena teori ini meyakini bahwa kegiatan mengirimkan pesan sama halnya dengan tindakan menyuntikan obat yang bisa langsung masuk ke dalam jiwa penerima pesan. Sebagaimana peluru yang ditembakan dan langsung masuk ke dalam tubuh. Singkatnya, menurut teori ini media massa amat perkasa dalam mempengaruhi penerima pesan. Teori S-R menggambarkan proses komunikasi secara sederhana yang hanya melibatkan dua komponen, yaitu media massa dan penerima pesan yaitu khalayak. Media massa mengeluarkan stimulus dan penerima menanggapinya dengan menunjukan respons sehingga dinamakan teori stimulus respons

Seperti halnya televisi siaran, tujuan khalayak menonton film adalah ingin memperoleh hiburan. Akan tetapi dalam film dapat terkandung fungsi informatif dan edukatif. Menurut Ardianto, Elvinaro \& Erdinaya, (2004: 34) faktor-faktor yang dapat menunjukkan karakteristik film adalah: layar lebar, pengambilan gambar, konsentrasi penuh dan identifikasi psikologis.

Karakteristik film tersebut adalah sebagai barikut:

Layar yang luas/lebar, film dan televisi sama-sama menggunakan layar, namun kelebihan media film adalah layarnya yang berukuran luas. Sehingga memberikan keleluasaan penonton untuk melihat adegan-adegan yang disajikan dalam film. Apalagi dengan 
kemajuan teknologi, layar film bisokop pada umumnya sudah tiga dimensi, sehingga penonton seolah-oleh melihat kejadian nyata dan tidak berjarak.

Pengambilan gambar, sebagai konsekuensi layar lebar, maka p engambilangambar atau shot, yakni pandangan menyeluruh

Konsentrasi penuh, dari pengalaman kita masing-masing disaat kita menontonfilm di bioskop, bila tempat duduk sudah penuh atau waktu main sudah tiba, pintu-pintu ditutup, lampu dimatikan di depan kita layar yang uas dengangambar-gambar film dan ceritanya.

Identifikasi psikologi, kita semua dapat merasakan bahwa suasana di gedung bioskop telah membuat pikiran dan perasaan kita laur dalamcerita yang disajikan. Karena penghayatankita yang amat mendelam seringkali secara tidak sadar kita menyamakan (mengidentifikasi) pribadi kita dengan salah seorang pemeran dalam film itu seolah-olah kita lah yang sedang berperan. Gejala ini menurut jiwa social disebut sebagaiidentifikasi psikologis. (Ardianto, Elvinaro \& Erdinaya, 2004)

\section{Rasa Nasionalisme}

Para ahli politik menganggap nasionalisme adalah sebuah ideologi yang sudah jelas, akan tetapi pada dasarnya nasionalisme adalah sebuah konsep yang "terbuka" untuk berbagai interpretasi, (Sudarsono, 2011, hlm.7). Nasionalisme dapat di bagi dua corak, yaitu nasionalisme Barat nasionalisme Timur. Nasionalisme barat adalah nasionalisme yang berada dalam masyarakat yang telah maju, sebagai upaya mengatasi situasi yang tidak menguntungkan. Sedangkan nasionalisme Timur adalah nasionalisme yang didesain untuk mengatasi keterbelakangan dengan cara meniru barat, tetapi memusuhi barat. Nasionalisme Timur ini tidak bersifat liberal ( Ranjabar, 2014: 240). Sedangkan menurut Hadiwijoyo nasionalisme dapat diartikan sebagai cinta dan bangga terhadap Negara kesatuan republik Indonesia (Hadiwijoyo, 2012: 16).

Menurut Budiyono (2007:209-21), terdapat empat bentuk nasionalisme yaitu: 1) Nasionalisme kemandirian bangsa, merupakan semangat bernegara dibangun untuk mewujudkan kejayaan bangsa. 2) Nasionalisme agama, yaitu suatu gerakan yang berupaya untuk memperoleh kemerdekaan melalui semangat keagamaan. 3) Nasionalme sekuler, merupakan suatu paham yang berupa untuk memperoleh kemerdekaan dengan tidak menyebutkan agama sebagai inspirasi gerakan, walaupun tidak menentang adanya 
peran agama dalam kegiatan politik. 4) Nasionalisme anti agama (komunis), merupakan nasionalisme anti agama tidak memberikan peran kepada agama bahkan agama tidak berperan dalam gerakan dan harus dijauhi.

Secara singkat landasan teori yang digunakan akan berfokus pada beberapa yang dijabarkan pada keranga pikir berikut:
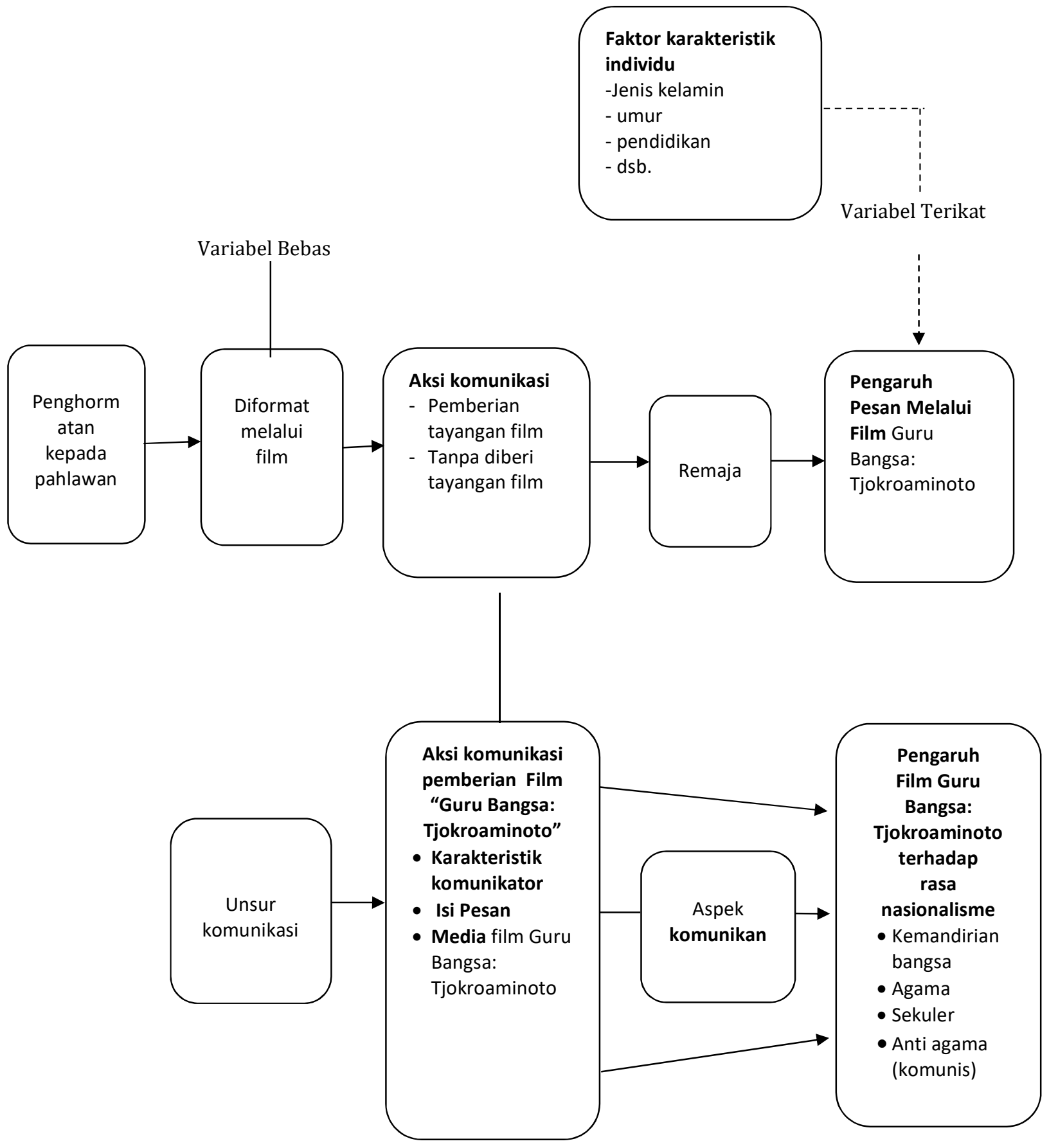

Gambar 2. Kerangka berfikir penelitian eksperimental kemasan pesan

70 | Pengaruh Film Guru Bangsa: Tjokroaminoto Terhadap... 


\section{Film Guru Bangsa: Tjokroaminoto}

\section{HIPOTESIS PENELITIAN}

Berdasarkan kerangka pemikiran tersebut, hipotesis dalam penelitian ini yaitu:

1. Terdapat perbedaan skor rasa Nasionalisme kemandirian bangsa, Nasionalisme agama, Nasionalme sekuler dan Nasionalisme anti agama (komunis) yang nyata antara kelompok eksperimen yang menyaksikan tayangan film Guru Bangsa: Tjokroaminoto dengan kelompok control yang tidak menyaksikan tayangan tayangan film Guru Bangsa:Tjokroaminoto.

2. Terdapat pengaruh nyata antara karakteristik komunikator, isi pesan, media dan aspek komunikan pada film Guru Bangsa: Tjokroaminoto dengan rasa nasionalisme.

\section{METODOLOGI PENELITIAN}

Penelitian ini dirancang dengan metode "Quasi-Eksperimental" melalui pendekatan kuantitatif bersifat eksplanatif korelasional, dengan peubah bebas yang dimanipulasi adalah film Guru Bangsa: Tjokroaminoto, sedangkan peubah terikat adalah rasa nasionalisme remaja siswa-siswi SMU Al Izhar Jakarta. Rancangan percobaan yang digunakan adalah The nonequivalent control group design.

Desain ini terdiri atas dua kelompok yaitu kelompok eksperimen dan kelompok kontrol yang masing-masing diberikan pretest dan posttest. Kelompok eksperimen sebelum melakukan posttest diberikan perlakuan terlebih dahulu. Langkah-langkah The nonequivalent control group design dapat dijabarkan sebagai berikut:

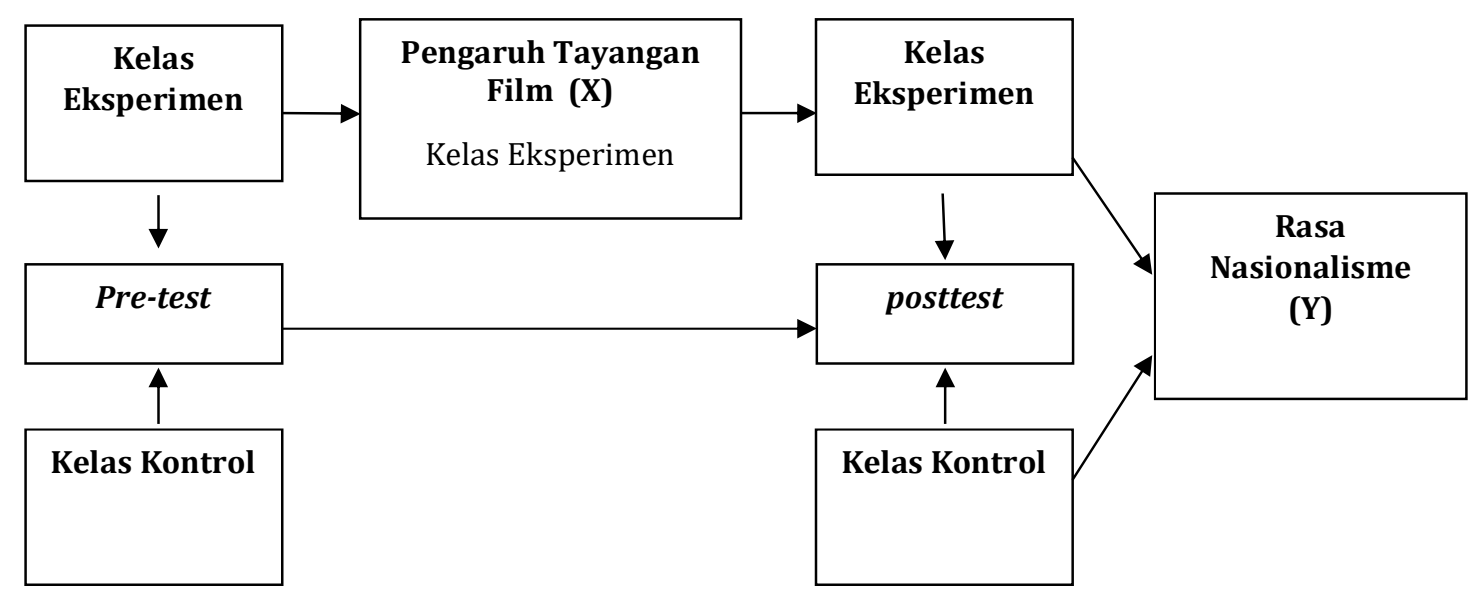


Gambar 4. Desain Penelitian Eksperimen Pengaruh Tayangan Film Guru Bangsa: Tjokroaminoto Terhadap Rasa Nasionalisme

Populasi dalam penelitian ini adalah siswa-siswi kelas XI Sekolah Menengah Umum Negeri (SMU N) 4, Kecamatan Tapos, Depok, dengan jumlah 359 siswa yang terdiri atas sembilan kelas.

Dalam penelitian ini penulis menggunakan rancangan sampling nonprobabilitas atau nonprobability sampling adalah sampel tidak melalui teknik random (acak). Pengambilan sampel dilakukan dengan membentuk 2 kelompok yaitu kelompok ekperimen dan kelompok kontrol yang masing-masing kelompok dibatasi 40 siswa, dengan cirri belum pernah menonton film Guru Bangsa: Tjokroaminoto.

\section{HASIL PENELITIAN}

Film Guru Bangsa: Tjokroaminoto dimulai dengan adegan Tjokroaminoto yang sedang diinterogasi sebagai pemimpin kaum bumi putera syarikat islam yang menjadi dalang kerusuhan dan ingin melakukan pemberontakan terhadap pemerintah Belanda. Adegan berikutnya menceritakan tentang masa kecil Tjokroaminoto yang menyaksikan kaumnya rakyat Indonesia disiksa oleh pemerintah Kolonial Belanda. Sehingga menimbulkan kesedihan yang mendalam pada diri Tjokro kecil yang merasa bangsanya telah ditindas oleh Kolonial Belanda.

Tjokro kemudian bekerja di Pelabuhan untuk menemukan arti hijrah yang dicarinya, dari saran seorang teman, Tjokro kemudian pindah ke Surabaya, tempat dimana ia akan menemukan arti kata hijrah.

Film Guru Bangsa:Tjokroaminoto selanjutnya menceritakan tentang kiprah Tjokroaminoto memimpin Syarikat Dagang Islam yang kemudian berganti dengan nama Syarikat Islam agar rakyat Indonesia bersatu dan mengangkat martabat masyarakat Indonesia.

Berikut adalah penjabaran mengenai pengaruh film Guru Bangsa: Tjokroaminoto terhadap Rasa Nasionalisme pada kelompok ekperimen. Setelah siswa mendapat perlakuan berupa penayangan film Guru Bangsa:

Tabel 2. Rataan skor Pengaruh Film Guru Bangsa: Tjokroaminoto terhadap 72 | Pengaruh Film Guru Bangsa: Tjokroaminoto Terhadap... 
Rasa Nasionalisme Remaja Siswa-Siswi SMU N 4 Depok (setelah perlakuan)

\begin{tabular}{|c|c|}
\hline Rasa Nasionalisme & Rataanskor* $^{*}$ \\
\hline Nasionalisme Kemandirian Bangsa & 2,91 \\
\hline Nasionlaisme Agama & 2,82 \\
\hline Nasionalisme Sekuler & 2,77 \\
\hline Nasionalisme Anti Agama (Komunis) & 2,49 \\
\hline Rasa Nasionalisme & $\mathbf{2 , 7 5}$ \\
\hline
\end{tabular}

Keterangan: *Interval skor 1,00 - 1,74 = Sangatburuk/sangatrendah; 1,75 - 2,49 = Buruk/rendah; $2,50-3,24=$ Baik/tinggi; 3,25 - 4,00 = Sangatbaik/sangattinggi

Dari hasil penelitian mengenai film Guru Bangsa: Tjokroaminoto terhadap Rasa Nasinalisme tersebut, terltera bahwa rataan skor yang diperoleh setelah menonton penayangan film Guru Bangsa: Tjokroaminoto adalah 2,75, yang berarti bahwa penayangan film Guru Bangsa: Tjokroaminoto berpengaruh terhadap rasa nasionalisme remaja khsusnya siswa SMU N 4 Depok. Dari segi Nasinalisme Kemandirian bangsa diperoleh rataan skor 2,91 yang berarti penayangan film Guru Bangsa: tjokroaminoto memberikan semangat bernegara untuk mewujudkan kejayaan bangsa dampak rasa nasionalisme kemandirian bangsa responden dalam hal ini kalangan remaja siswa-siswi SMU N 4 Depok. Rasa Nasionalisme agama, setelah penayangan film Guru Bangsa: tjokroaminoto, diperoleh rataan 2,82 yang berarti penayangan film Guru Bangsa: tjokroaminoto berpengaruh terhadap rasa Nasionalisme agama responden dalam hal ini kalangan remaja SMU N 4 Depok. Dari segi Nasionalisme Sekuler setelah penayangan film Guru Bangsa: Tjokroaminoto diperoleh skor 2,77 yang berarti penayangan film Guru Bangsa: Tjokroaminoto berpengruh terhadap rasa Nasionalisme Sekuler dalam hal ini responden remaja siswa-siswi SMU N 4 Depok. Sedangkan dari segi Rasa Nasionalisme Anti Agama (komunis) setelah penayangan film Guru Bangsa: Tjokroaminoto, diperoleh skor 2,49 yang berarti penayangan film Guru Bangsa: tjokroaminoto tidak berpengaruh terhadap Rasa Nasionalisme Anti Agama (Komunis) bagi remaja, dalam hal ini siswa-siswi SMU N 4 Depok

Hipotesis pertama penelitian ini adalah terdapat perbedaan skor rasa Nasionalisme kemandirian bangsa, Nasionalisme agama, Nasionalme sekuler dan Nasionalisme anti agama (komunis) yang nyata antara kelompok eksperimen yang menyaksikan penayangan film Guru Bangsa: Tjokroaminoto dengan kelompok kontrol yang tidak menyaksikan penayangan tayangan film Guru Bangsa: Tjokroaminoto. 
Selanjutnya adalah untuk mengetahui perbedaan seberapa besar pengaruh penayangan film Guru Bangsa: Tjokroaminoto terhadap rasa nasionalisme

Tabel 3. Pengaruh Film Guru Bangsa: Tjokroaminoto terhadap Rasa Nasionalisme Remaja Siswa-Siswi SMU N 4 Depok Sebelum (Pretest) dan Sesudah Perlakuan (Posttest)

\begin{tabular}{|c|c|c|c|c|c|c|c|}
\hline \multirow{2}{*}{$\begin{array}{c}\text { Rasa } \\
\text { Nasionalisme }\end{array}$} & \multicolumn{2}{|c|}{ Pretest } & \multicolumn{2}{|c|}{ Posttest } & \multirow{2}{*}{ Beda } & \multirow{2}{*}{$\begin{array}{c}\text { Persen } \\
\text {-tasi } \\
(\%)\end{array}$} & \multirow{2}{*}{$t_{\text {hitung }}$} \\
\hline & Kontrol & Eksp & Kontrol & Eksp & & & \\
\hline $\begin{array}{l}\text { Nasinalisme } \\
\text { Kemandirian } \\
\text { Bangsa }\end{array}$ & 2.56 & 2.53 & 2.61 & 2.91 & 0.30 & 11.44 & $5.923^{* *}$ \\
\hline $\begin{array}{l}\text { Nasionalisme } \\
\text { Agama }\end{array}$ & 2.49 & 2.42 & 2.54 & 2.82 & 0.28 & 9.96 & $5.059 * *$ \\
\hline $\begin{array}{l}\text { Nasionalisme } \\
\text { Sekuler }\end{array}$ & 2.44 & 2.56 & 2.51 & 2.77 & 0.26 & 9.94 & $4.238^{* *}$ \\
\hline $\begin{array}{l}\text { Nasionalisme } \\
\text { Anti Agama } \\
\text { (Komunis) }\end{array}$ & 2.29 & 2.34 & 2.29 & 2.49 & 0.20 & 9.88 & 2.186 \\
\hline Total & 2.46 & 2.46 & 2.49 & 2.75 & 0.28 & 10.44 & $6.183^{* *}$ \\
\hline
\end{tabular}

Keterangan: ${ }^{* *}=$ Signifikan pada level 0,01

Dari Tabel 3 di atas terlihat bahwa tidak ada perbedaan antara kelompok kontrol dengan kelompok ekperimen sebelum pemberian penayangan film Guru Bangsa: Tjokroaminoto, artinya baik kelompok Kontrol maupun kelompok eksperimen memiliki pengetahuan yang hampir sama.

Setelah pemberian perlakuan berupa penayangan film Guru Banga; Tjokroaminoto, responden pada kelompok eksperimen dan kelompok kontrol yang tidak diberi perlakuan terlihat pada table tersebut terdapat perbedaan yang nyata antara kedua kelompok tersebut.

Pada Table 3 tersebut dapat dilihat bahwa kelompok eksperimen yang diberi perlakuan memiliki pengetahuan lebih banyak yang berbeda nyata dengan kelompok control yang tidak diberi perlakuan. Secara keseluruhan memperlihatkan bahwa bahwa kelompok eksperimen memiliki pengetahuan lebih banyak yang berbeda nyata dengan kelompok 74 | Pengaruh Film Guru Bangsa: Tjokroaminoto Terhadap... 
kontrol. Dengan demikian hipotesis pertama dalam penelitian ini diterima, yakni terdapat perbedaan nyata rata-rata Rasa Nasionalisme Kemandirian Bangsa, Nasionalisme Agama, dan Nasionalisme Sekuler. Sementara, rasa Nasionalisme Anti Agama (komunis) tidak memeiliki perbedaan yang nyata antara Kelompok kontrol dan Kelompok eksperimen setelah perlakukan, dengan selisih masing-masing 0,30 (11,44\%), 0,26 (9,94\%), dan 0,28 (9,96\%), yang signifikan pada level 0,01. Sementara, rasa Nasionalisme Anti Agama (Komunis) memiliki selisih 0,20 (10,44\%)

Secara keseluruhan faktor-faktor yang terdiri atas karakteristik komunikator, isi pesan, media, dan aspek komunikan berpengaruh terhadap rasa nasionalisme remaja khususnya Siswa-siswi SMU N 4 Depok. artinya faktor-faktor tersebut berpengaruh pada rasa nasionalisme remaja khususnya siswa-siswi SMU N 4 Depok.

Apabila dilihat lebih rinci, faktor isi pesan mempunyai skor 2,43. Halini berarti bahwa isi pesan berpengaruh terhadap Rasa Nasionalisme Kemadirian Bangsa, rasa Nasionalisme Agama dan rasa Nasionalisme sekuler. Hanya Rasa Nasionalisme Anti Agama (Komunis) yang secara keseluruhan tidak dapat dipengaruhi baik oleh faktor komunikator, isi pesan, media dan aspek komunikasn, seperti terlihat pada Tabel 4.

Karakteristik komunikator mempunyai skor 2,49. terdiri atas expertise (ahli), trustworthiness (dapat dipercaya), dan acceptability (dapat diterima) memiliki skor rendah. Dari faktor Karakteristik Komunikator, hanya aspek expertise (keahlian) yang memiliki skor tinggi yaitu sebesar 2,60. Sedangkan faktor Media, memiliki skor 2,56, Faktor Media yang terdiri atas Layar yang luas/lebar, Pengambilan gambar, Konsentrasi penuh, Identifikasi psikologkebutuhan memiliki skor tinggi, kecuali pada aspek Konsentrasi Penuh yang memiliki skor 2.40 ang berarti berpengaruh rendah terhadap rasa Nasionalisme. Skor faktor media tersebut dapat dilihat pada Tabel 4.

Untuk lebih jelasnya, secara rinci dapat dijabarkan sebagai berikut:

Tabel 4. Faktor-Faktor dalam Penyangan Film Guru Bangsa: Tjokroaminoto yang Berpengaruh Terhadap Rasa Nasionalisme

\begin{tabular}{|l|c|}
\hline \multicolumn{1}{|c|}{ Faktor-faktor yang berpengaruh } & Rataan skor* \\
\hline Karakteristik komunikator & 2,49 \\
Credibility expertise & 2,60 \\
Trustworthiness & 2,45 \\
Acceptability & 2,42 \\
\hline Isi pesan & \multicolumn{1}{|c|}{2,43} \\
\hline
\end{tabular}




\begin{tabular}{|l|l|}
\hline Lambang yang sama & 2,43 \\
Membangkitkan kebutuhan & 2,41 \\
Mudah dilakukan & 2,45 \\
\hline Media & 2,57 \\
Layar yang luas/lebar & 2,72 \\
Pengambilan gambar & 2,40 \\
Konsentrasi penuh & 2,55 \\
Identifikasi psikologi & 2,60 \\
\hline Aspek komunikan & 2,69 \\
Kesesuaian penerima pesan & 2,80 \\
Kesesuaian isi pesan & 2,67 \\
Ketepatan waktu & 2,67 \\
Kesesuaian media & 2,60 \\
Kesesuaian format & 2,54 \\
Kejelasan sumber & 2,67 \\
\hline Rataan skor total & 2,50 \\
\hline
\end{tabular}

Keterangan:*Interval skor 1,00-1,74 = sangat rendah; 1,75-2,49 = rendah; 2,50-3,24 = tinggi; $3,25-4,00=$ sangat tinggi

\section{SIMPULAN}

Dari hasil penelitian yang telah dipaparkan, dapat ditarik beberapa kesimpulan yang berkaitan dengan pengaruh film Guru Bangsa: Tjokroaminoto terhadap rasa nasionalisme remaja siswa-siswi SMAN 4 Depok, sebagai berikut:

1. Pengaruh film Guru Bangsa: Tjokroaminoto terhadap rasa nasionalisme remaja siswa-siswi SMUN 4 Depok, secara keseluruhan tinggi baik dari segi Nasionalisme Kemandirian Bangsa, Nasionalisme Agama, dan Nasionalisme Sekuler. Sementara penayangan film Guru Bangsa: Tjokroaminto terhadap rasa Nasionalisme Anti Agama (Komunis) rendah atuau tidak terdapat pengaruh.

2. Terdapat perbedaan nyata pada rasa Nasionlaisme Kemandirian Bangs, Nasionalisme Agama dan Nasionalisme Sekuler, serta tidak ada perbedaan untuk aspek Nasionalisme Anti Agama (Komunis) antara siswa-siswi dalam kelompok eksperimen yang mendapat tayangan film Guru Bangsa: Tjokroaminoto dengan kelompok kontrol yang tidak mendapat tayangan film Guru Bangss: Tjokroaminoto. 
3. Secara umum faktor-faktor dalam film Guru Bangsa: Tjokroaminoto yang berpengaruh tinggi terhadap rasa nasionalisme remaja siswa-siswi SMU N 4 Depok adalah faktor Media dan aspek komunikan, sedangkan faktor karakteristik komunikator dan Isi Pesan dalam film Guru Bangsa: Tjokroaminoto berpengaruh rendah terhadap rasa nasionalsme remaja siswa-siswi SMUN 4 Depok.

\section{SARAN}

Saran terkait pengaruh film Guru Bangsa: Tjokroamioto terhadap rasa nasionalisme remaja sebagai berikut:

1. Cerita dalam film Guru Bangsa: Tjokroaminoto terlalu banyak yang melompat sehingga perlu menonton beberapa kali agar mudah dimengerti. Alur cerita perlu diberi variasi agar lebih menarik sehingga durasi film 150 menit tidak membosankan untuk sebuah film sejarah kepahlawanan.

2. Unsur2 lain seperti keterangan perpindahan dari satu adegan ke adegan lain perlu diberi keterangan atau dimasukkan dalam dialog agar lebih mudah dipahami serta perlu pembukatian sejarah yang lebih akurat agar tidak terjadi kesalahan informasi

3. Diperlukan penelitian lanjutan untuk mengetahui film sejarah pahlawan yang diminati yang berfungsi selain sebagai hiburan juga sebagai pembalajaran sejarah

\section{DAFTAR PUSTAKA}

Ardianto, Elvinaro dan Lukiati Komala Erdinaya. 2004. Komunikasi Massa Suatu Pengantar. PT Remaja Rosdakarya, Bandung.

Budiono. 2007. Nilai-nilai Kepribadian dan Kejuangan Bangsa Indonesia. Bandung: Alfabeta.

Cangara, Hafied. 2009. Pengantar Ilmu Komunikasi. Jakarta: PT.Raja Grafindo Persada.

Hadiwijoyo, Suwelo. 2013. Ajaran-Ajaran Spektakuler Bung Karno Dan Pak Harto. Jogjakarta: IRCiSoD (Diva Press).

Ranjabar, Jacobus. 2014. Profil Indonesia. Bandung: Alfabeta

Sudarsono, Juwono. 2011. Nasionalisme dan Ketahanan Budaya di Indonesia Sebuah Tantangan. Jakarta: LIPI Press. 